\title{
Impulsive Noise Impact on ADSL2+ Systems
}

\author{
Lamartine V. de Souza, Igor M. Negrão, Ronaldo F. Zampolo, \\ Agostinho L. S. Castro, João C. W. A. Costa and Jaume R. I Riu
}

\begin{abstract}
This paper aims to characterize how the impulse noise impacts on services and applications for a broadband system using an ADSL2+ (Asymmetric Digital Subscriber Line, extended bandwidth) loop. The first approach employs the impulse noise defined in the G.996.1 (Test Procedures for DSL Transceivers) and TR-048 (ADSL Interoperability Test Plan) recommendations from ITU-T and DSL Forum, respectively. The second approach assesses system performance under REIN (Repetitive Electrical Impulse Noise) disturbance, which often occurs in the PSTN (Public Switched Telephone Network). REIN does not disturb the telephone service, however being quite harmful to ADSL. Metrics at packet level, as packet rate, lost packet count, bandwidth, short-term average transfer delay, and errored seconds, are used in order to characterize the DSL loop subjected to the referred noise impairments. After that, perceptual metrics are used along with QoS (Quality of Service) objective metrics to identify the impulse noise impact to the final user, leading to a QoE (Quality of Experience) analysis of the system.
\end{abstract}

Keywords-broadband networks, nonstationary noise, DSL systems, measurements, quality of service, quality of experience.

\section{INTRODUCTION}

The xDSL access technologies have been developed by the telephone companies to provide high-speed data rates over conventional telephone wires. The term xDSL covers a number of similar yet competing forms of DSL, including ADSL, SHDSL (Single-Pair High Speed DSL), HDSL (High-Bit-Rate DSL), and VDSL (Very High Rate DSL) [1].

As DSL works with relatively high frequencies, when compared with regular telephony, its signal is highly susceptible to external noise sources. Thus, an understanding about the behavior of different kinds of noise and their respective effects on network performance are extremely useful for designing both well established DSL systems (ADSL, ADSL2+) and those of upcoming generation (VDSL, VDSL2).

During the last years, crosstalk has been considered the main impairment to DSL services. However, due to the development of efficient crosstalk control techniques, other types of noise have gained importance, such as radio frequency interference (RFI), impulsive noise (IN), REIN, and isolated burst of electrical noise (IBEN), just to mention a few [2] [3].

The major part of noise investigation relies on the RFI impact on xDSL communications. In [4] the authors detail a theoretical approach, and describe a corresponding implementation, to mitigate strong narrowband RFI in the analog domain, i.e., before the modem ADC (analog-to-digital converter). In [5] and [6] the authors have presented a digital frequency domain RFI cancellation scheme for DMT (Discrete Multitone) based VDSL systems. In [7] is presented two novel narrowband and wideband common mode noise cancellation techniques for xDSL systems.

In turn, IN has also been investigated by many researchers for a relatively long time. In [8], the ATM cell error performance over

Lamartine V. de Souza, Igor M. Negrão, and João C. W. A. Costa are with Applied Electromagnetism Laboratory (LEA); Agostinho L. S. Castro, and Ronaldo F. Zampolo are with Signal Processing Laboratory (LaPS), Federal University of Pará (UFPA), Belém/Pará, Brazil, E-mails: \{lvsouza, igor, zampolo, agcastro, jweyl $\} @$ ufpa.br; Jaume R. I Riu is with Ericsson AB, Älvsjö, Sweden, E-mail: jaume.rius.i.riu@ericsson.com .
DSL in the presence of IN is studied. In [9], an analysis of error statistics for both ADSL and SHDSL (Single-Pair High Speed DSL) transmitted data under IN attack is reported. In [10], the authors have presented a framework for estimation of data errors due to IN in XDSL systems, where the analysis is based on a DSL-oriented impulsive noise model derived from experimental data collected from both German and British telephone networks. In [11] the author has simulated the ADSL transmission performance under IN. In [12] is analyzed how the $\mathrm{C} 1$ and $\mathrm{C} 2 \mathrm{IN}$ impacts on services and applications for an ADSL2+ loop from an experimental standpoint.

REIN is another type of noise which may seriously degrade an ADSL2+ connection. Such a noise occurs in broadband bursts, has random nature, covers a large range of frequencies and is commonly generated by household equipment, e.g. TVs, VCRs, TV receivers, dimmer switches, christmas tree lights. Thermostats, thunderstorms and electric fences can also generate REIN. Identifying a REIN source is often a rather difficult and costly task [13], but undoubted very important, since a single REIN source can affect many broadband users.

This paper aims to characterize how the IN (C1, C2 and REIN types) impacts on an ADSL2+ broadband system. Particularly, the objective is to collect experimental data concerned to the behavior of an ADSL2+ system under more realistic but controlled line conditions. For this purpose, an experimental setup was built at UFPA that consists of noise generator, traffic generator, wireline simulators, modems and DSLAM (digital subscriber line access multiplexer). This study of the IN impact is performed by: (a) analyzing objective parameters at level of packets (QoS analysis); and (b) analyzing perceptual parameters in order to classify the system accordingto the final user viewpoint (QoE analysis).

The remaining part of this paper is organized as follows. In Section II, we explain the methodology for the tests using C1 and C2 impulses defined in [14]. In Section III, we explain the methodology for the tests using REIN. The results obtained are shown in Section IV. Finally, conclusions and some topics for future research are drawn in Section V.

\section{Methodology for tests using C1 And C2 Impulses}

The test described next is based on the guidelines given in Section 8.8 of [15] and has the objective of observing the DSL operation in the presence of IN events. In this case, two kinds of IN defined in [14], known as C1 and C2, are used.

The setup adopted to perform the measurements is shown in Fig. 1. The equipments described in Fig. 1 as well as their functions are detailed in Table I.

Traffic generated on AX/4000 is an IP stream with a datagram length of 980 bytes and rates for upstream (798.19 kbps) and downstream (4100.26 kbps), which conforms to the ADSL2+ standard [16]. The frequency range used is that of the ADSL2+ recommendation: from $4.3125 \mathrm{kHz}$ to $2.208 \mathrm{MHz}$.

The packet rate and lost packet count are collected by AX/4000. Packet rate is defined as the number of packets transmitted over run time and lost packet count as the number of packets that are lost (except out-of-sequence packets). 


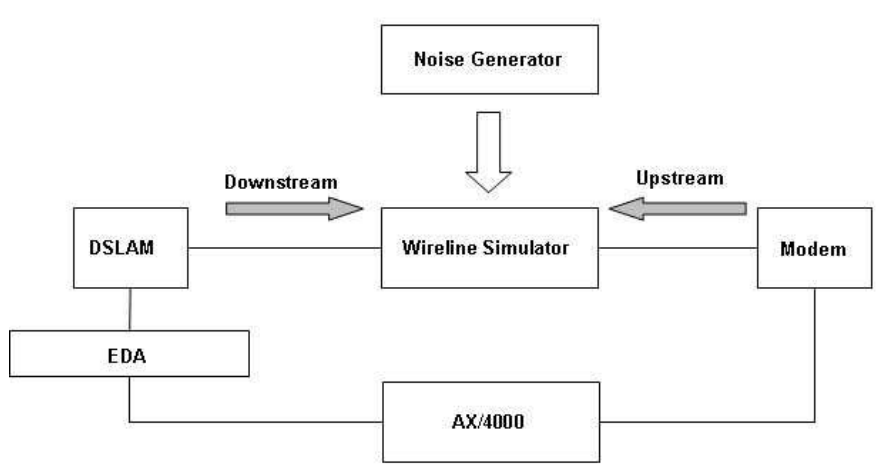

Fig. 1. Equipments used in $\mathrm{C} 1$ and $\mathrm{C} 2$ measurements.

Table I

EQUIPMENTS USED IN C1 AND C2 MEASUREMENTS.

\begin{tabular}{l|l}
\hline \hline Equipment & Function \\
\hline $\begin{array}{l}\text { Noise Generator - DLS 5500 } \\
\text { from Spirent Communica- } \\
\text { tions }\end{array}$ & $\begin{array}{l}\text { Generation of IN, white } \\
\text { noise and crosstalk. }\end{array}$ \\
\hline $\begin{array}{l}\text { Wireline Simulator - } \\
\text { ADSL2+ ETSI DLS } \\
410 E 3 \quad \text { from Spirent } \\
\text { Communications }\end{array}$ & $\begin{array}{l}\text { Reproduction of the AC and } \\
\text { DC characteristics of twisted } \\
\text { pair copper telephony cable } \\
\text { using passive circuitry (R, L } \\
\text { \& C). }\end{array}$ \\
\hline $\begin{array}{l}\text { DSLAM Ericsson } \\
\text { EDN312xp }\end{array}$ & CO functions in the system. \\
\hline Ericsson ECN320 & CO functions in the system. \\
\hline $\begin{array}{l}\text { Modem - Ericsson ADSL2+ } \\
\text { Come Gateway HM410dp }\end{array}$ & $\begin{array}{l}\text { Generation and analysis of } \\
\text { traffic (downstream and up- } \\
\text { stream) in the system. }\end{array}$ \\
\hline $\begin{array}{l}\text { AX/4000 from Spirent Com- } \\
\text { munications }\end{array}$ \\
\hline \hline
\end{tabular}

Tests has been carried out in upstream and downstream directions, and the impulse noises are injected in $\mathrm{CO}$ and CPE sides with pulse amplitude of $50 \mathrm{mV}$ and $100 \mathrm{mV}$. All the tests are done by injecting the IN impairments at $t=20 \mathrm{~s}$. Thus, the DSL transmission can be observed with and without noise impairments.

In this experiment we have used a HDSL system along with white noise disturbance, the latter applied continuously at $\mathrm{CO}$ side. The impulse noises $\mathrm{C} 1$ and $\mathrm{C} 2$ are injected into the circuit at both $\mathrm{CO}$ and CPE ends of the loop simulator, but not simultaneously.

Before testing, the DSL units are trained with the disturber interference defined in [15]. CO side impairments are: $20 \mathrm{HDSL}$ NEXT (near-end crosstalk) disturbers with total power of $-45.8 \mathrm{dBm}$ with the operation frequency ranging from 0 to $1.544 \mathrm{MHz},-140.0$ $\mathrm{dBm} / \mathrm{Hz}$ white noise, and 15 ADSL $\mathrm{C} 1$ and $\mathrm{C} 2$ impulses, spaced at least 1 second apart. The last one is used as impairment at CPE side. The wireline simulator is set to a loop with $2700 \mathrm{~m}$ of $0.4 \mathrm{~mm}$ wire.

\section{Methodology FOR TESTS USING REIN impUlses}

\section{A. Measurement setup}

In order to specify a measurement scenario, the setup proposed in [17], [18] and [19] is repeated with a little modification: noise is injected in the middle of the loop by means of two wireline simulators. Figure 2 shows the measurement setup used.

The elements depicted in Fig. 2 are: the traffic generator in charge of the generation and analyzing downstream and upstream traffics; the wireline simulator ADSL2+ [20], which simulates the local loop to be analyzed; the noise generator that is responsible for generating and injecting interference into the line; the DSLAM, which transmits ADSL/ATM signals through the twisted pair loop (in this case, the

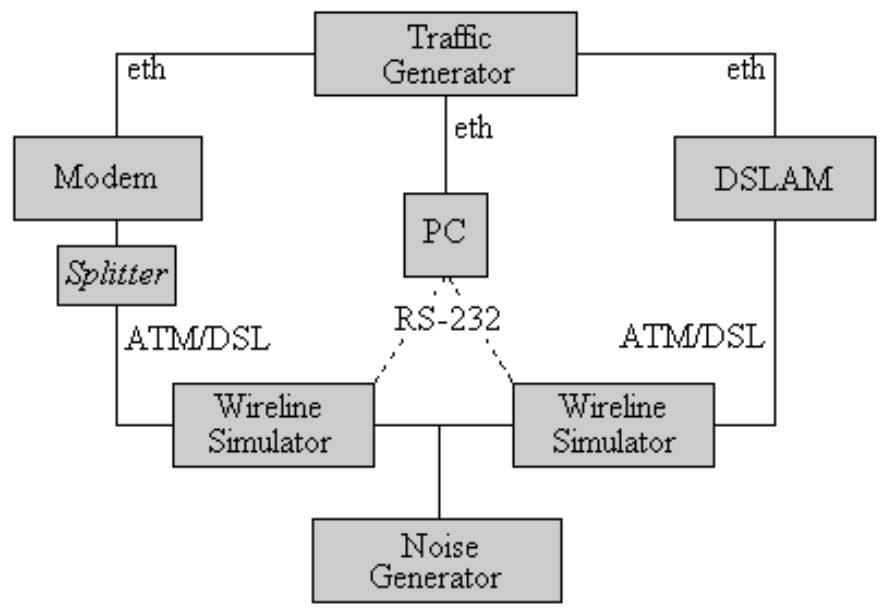

Fig. 2. Measurement setup.

wireline simulator); the modem has the function of modulating and demodulating the signal at the subscriber side; the splitter that is responsible to separate signals of voice and data; and finally, the PC which is used to manage the measurements via software.

\section{B. Local loops}

The loop topologies considered for testing are those of the Telebrás recommendation [21]. In this way, five different loops are used in the experimental procedures. The referred loop topologies are depicted in the Fig. 3.

\section{Telebrás \#1 \\ CO}

$0.4 \mathrm{~mm} / 2.9 \mathrm{~km}$

Telebrás \#2

$\mathrm{CO}$

$0.5 \mathrm{~mm} / 3.85 \mathrm{~km}$

Telebrás \#3

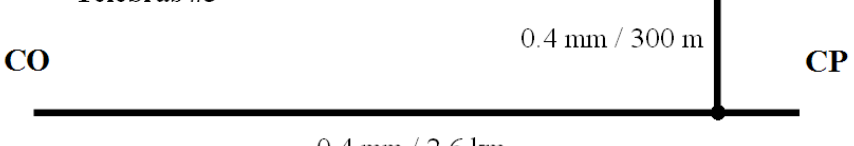

$0.4 \mathrm{~mm} / 2.6 \mathrm{~km}$

Telebrás \#4

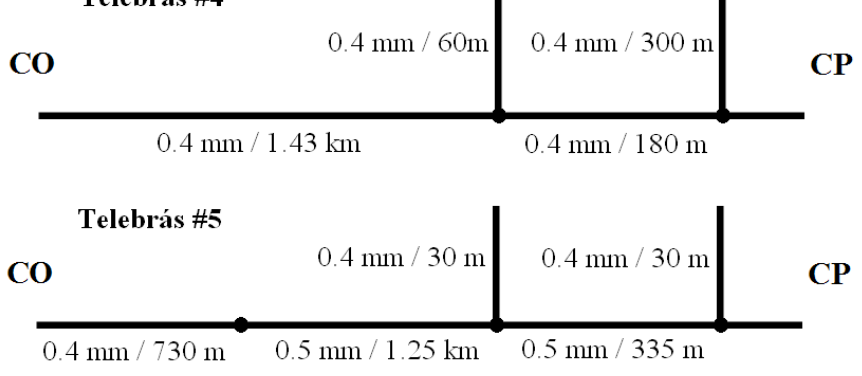

Fig. 3. Telebrás local loop topologies considered for testing.

\section{Performance variables}

In order to provide a QoS evaluation of an ADSL2+ system subjected to REIN, we have chosen some figures which are compared 
with reference values. In this paper, we have considered noiseless operation to assess the impact of REIN in the transmission. These tests evaluate four variables: packet rate (IP packet rate transmitted by DSLAM), bit rate (achieved by CPE), lost packet counter (number of packets that are lost, less out-of-sequence packets) and maximum transfer delay (maximum transfer time in milliseconds since the analyzer is started). By analysing such measurement figures, a QoS evaluation if achieved by comparison. Table II shows the traffic generator's transmission setup for the performed experiments. Note that the overall data rate is lower than the transmitted one due to losses introduced by the tested scenarios.

Table II

TrafFic/AnAlyzer Generator CONFiguration

\begin{tabular}{c|c|c}
\hline \hline Fixed Variables & Upstream & Downstream \\
\hline \hline Packet Rate & $18,84 \mathrm{p} / \mathrm{s}$ & $74,68 \mathrm{p} / \mathrm{s}$ \\
\hline Max. Bandwidth & 1,50 & 6,00 \\
\hline ․․ Lax. Load & 1,53 & 6,12 \\
\hline Datagram Bit Rate & $147,44 \mathrm{~kb} / \mathrm{s}$ & $586,72 \mathrm{~kb} / \mathrm{s}$ \\
\hline Line Bit Rate & $150,15 \mathrm{~kb} / \mathrm{s}$ & $599,86 \mathrm{~kb} / \mathrm{s}$ \\
\hline Packet Length & $1000 \mathrm{bytes}$ & $1000 \mathrm{bytes}$ \\
\hline \hline
\end{tabular}

\section{Measurement procedure}

When working with measurements we must keep in mind the importance of the statistical reasoning on collected data in order to extract meaninful information from them. In this paper we will perform ten measurements for each modification in the test setup. This small number of measurements, though not enough for a complete statistical rising (hundreds of measurements would be necessary for that), is sufficient for testing consistency by, for instance, using Dixon's test (detection of outliers) [22] and estimation of confidence interval that was constructed based on Students distribution [17].

\section{E. QoS analysis}

In order to investigate the REIN influence in the ADSL2+ transmission, experiments have been conducted considering the setup shown in Fig. 2. Then, by analyzing the chosen performance variables, we intend to objectively typify the effects of REIN in ADSL2+ systems for the different scenarios of Telebrás standard before mentioned.

\section{F. QoE analysis}

QoE and QoS terms are often interchangeably used, but are actually two different concepts. QoE is the overall performance of a system from the user standpoint. In other words, QoE is a measure of end-toend performance at the service level from the user perspective and an indication of how well the system meets the user needs [23]. There are some QoE metrics, being the MOS (Mean Opinion Score) one of the most used [23].

The MOS is typically used as a representation of the perceptual impact (users' quality of experience) due to various forms of service degradation [23]. In turn, although QoS metrics can be measured easier than MOS, they provide less information. QoE is also studied and formally defined in the ITU-T Study Group [24], specifically in Question 13/12 [25] and in the ATIS IPTV Interoperability Forum (IIF), QoS Metrics Task Force (QoSM) [26]. In this paper, the QoE is assessed by analysing the quality of digital videos. According to [23], QoE of a video can be measured in three ways:

- Subjectively, by using a controlled viewing experiment and participants who grade the quality using rating scales such as MOS;
- Objectively at the service layer, by using electronic test equipment to measure various aspects of the overall quality of the video signal (e.g. PSNR );

- Indirectly, by using measurements of network impairments (loss, delay, jitter, duration of the defect) to estimate the impact on video quality, where there is an established relationship between QoE and QoS.

Then, three tests are performed with video traffic in an experimental ADSL2+ network:

- Experiments with videoconference service, using the software Skype [27];

- Experiments with video hosting sites that use buffered videos (in our experiment, YouTube) [28], and experiments with sites of on demand videos (in our experiment, CNN) [29];

- Analysis of impact on network games (in our experiment, Wolfeinstein: Enemy Territory).

Interactive games are widely used for network performance tests, because in this type of game an action generates a response that should be noticed immediately. In such an application, the end to end response time (SRT - System Response Time) is the key parameter for the QoE evaluation. The SRT is the time that a system needs to detect and process an event started by an user, i.e. transport the referred event signals through network to the game server, process them, and send an update of current game state back to the client [TR-qoe].

Based on the SRT, the above mentioned game has a variable called ping that can be viewed anytime of the game. When the ping is high, we start perceiving frame loss and difficulty to play, what can happen when the system suffers any type of degeneration or is accessing a server very distant.

The aim is to classify the service via MOS for different REIN profiles, by using the knowledge of QoS analysis, attempting to identify some QoS variables that affect directly the final user experience.

\section{RESUlts}

\section{A. Results of tests using $C 1$ and $C 2$ impulses}

Results for $\mathrm{C} 1$ and $\mathrm{C} 2$ measurements are shown in Figs. 4 and 5. In Fig. 4, the downstream packet rate for $\mathrm{C} 1$ impulses of $50 \mathrm{mV}$ and $100 \mathrm{mV}$ on $\mathrm{CO}$ side is shown. Note that the IN injection has not impacted on DSL transmission, as can be seen by the small variation of packet rate. Similar results have been obtained for upstream traffic, being also observed for other three different situations: $\mathrm{C} 1$ injection at $\mathrm{CPE}$ side; $\mathrm{C} 2$ injection at $\mathrm{CO}$ side; and $\mathrm{C} 2$ injection at $\mathrm{CPE}$ side.

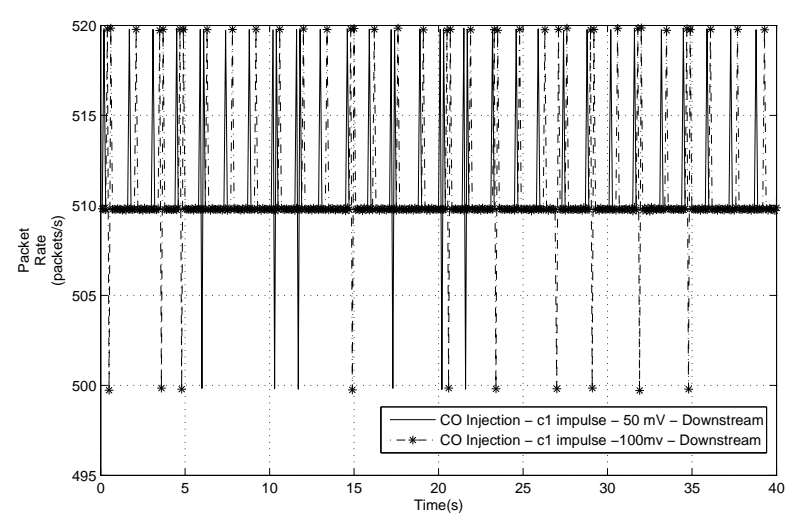

Fig. 4. Downstream packet rate for $\mathrm{C} 1$ injection at $\mathrm{CO}$ side. 
Figure 5 shows downstream lost packet count, when using $\mathrm{C} 1$ of $50 \mathrm{mV}$ and $100 \mathrm{mV}$ at $\mathrm{CO}$ side. Note that $\mathrm{C} 1$ impulse does not cause any lost packet on transmission. Like the packet rate metric, similar behavior happens in upstream traffic and in other three different situations: $\mathrm{C} 1$ injection at $\mathrm{CPE}$ side; $\mathrm{C} 2$ injection at $\mathrm{CO}$ side; and $\mathrm{C} 2$ injection at CPE side.

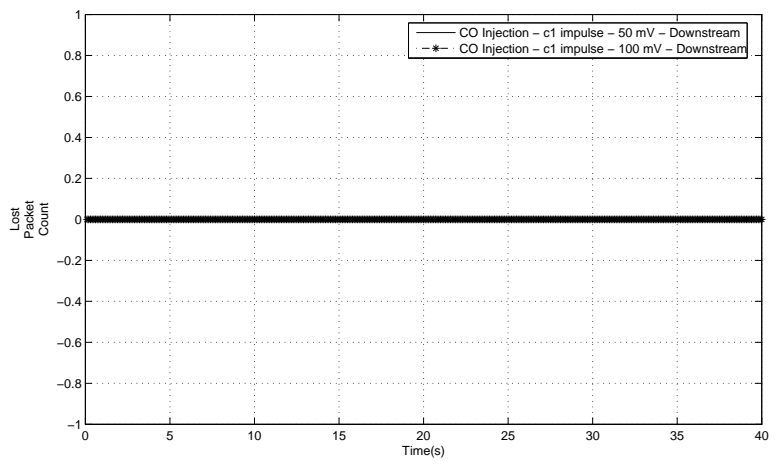

Fig. 5. Downstream lost packet for $\mathrm{C} 1$ injection at $\mathrm{CO}$ side.

An extended research on the $\mathrm{C} 1$ and $\mathrm{C} 2$ impulses impact on DSL transmission can be found in [12], where other metrics like bandwidth, short-term average transfer delay, errored seconds, and severely errored seconds are used to characterize the DSL loop under the noise impairments.

\section{B. Results of tests using REIN impulses}

In the performed tests, the REIN profile has a length of $1 \mathrm{~ms}$, $85 \mathrm{dBm} / \mathrm{Hz}$ PSD (power spectral density) and only one occurrence per second. For the QoE tests we have used one additional REIN profile with a length of $100 \mu \mathrm{s},-95 \mathrm{dBm} / \mathrm{Hz}$ PSD and one hundred occurrences per second. In all cases, we have analyzed the worst case, considering the noise influence during all the transmission. Worthy of mention is that if bit rate is evaluated, the conclusion will be the same one of packet rate analysis.

1) QoS Results: For upstream we have not observed any significant changes both in packet rate and lost packets for loops 1 to 4. However, loop 5 has presented a very expressive variation in the mentioned variables around 36 seconds of measurement time. Such a level of degradation has led to a modem connection loss. By analyzing the upstream transmission, we note that the delay achieves higher values than the noiseless transmission case for loops 1 and 2 . In turn, for loops 3, 4 and 5 (remembering that these loops contain bridge-tap), delay tends to be lower than the noiseless case.

For downstream the impact of REIN is more perceptible than for upstream. Such a behavior can be explained considering that downstream has a larger bandwidth than upstream. In this way, by analyzing packet rate we can observe that the loops 1,2 and 4 have presented constant variations in the packet rate. Such a variable data for loop 3 is depicted in Fig. 6, where one can note a visible moment of instability at the beginning of measurement until around 16 seconds, when the modem attained synchronization, then maintaining similar levels of loops 1, 2 and 4. Finally, for loop 5 (Fig. 7), a larger impact is verified, where we can see a decrease of packet rate level around 33 seconds of measurement time. This fact, combined with the results for upstream, indicates a connection loss at that moment.

Concerning the lost packets, in general, all the loops have achieved a constant low level of loss. Loops 1, 2, 3 and 4 have presented, at different moments, a moment of expressive loss (Fig. 8). Loop 5 has

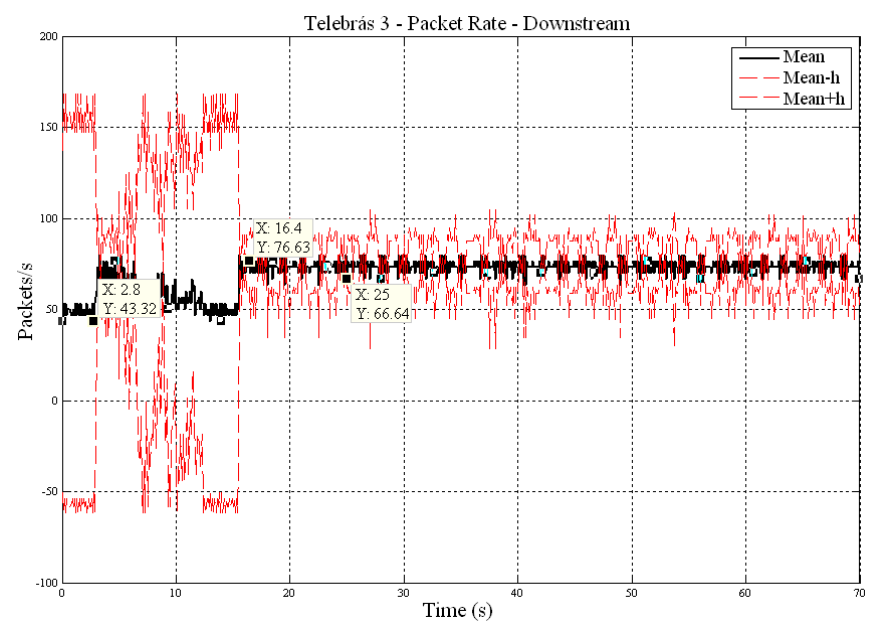

Fig. 6. Packet rate for loop 3 with influence of REIN.

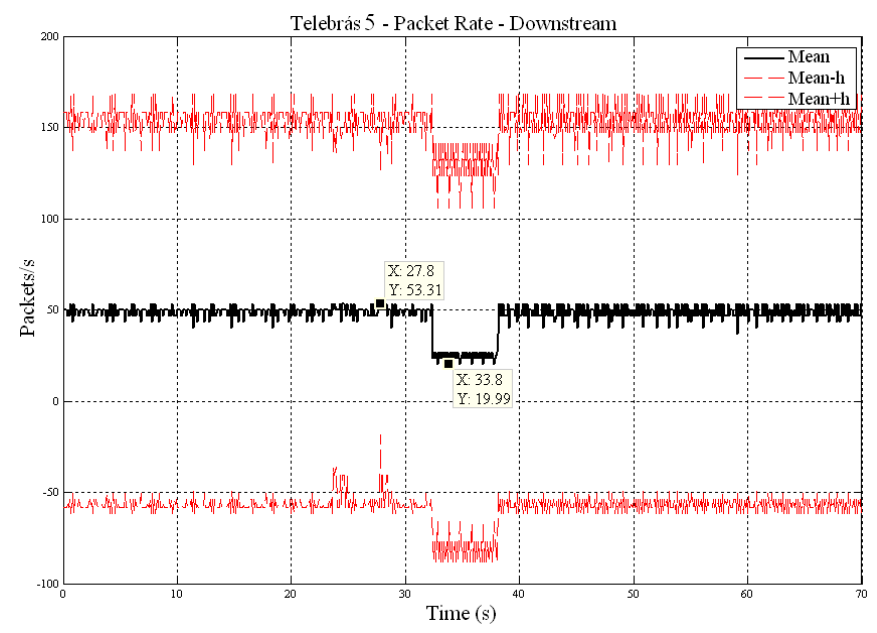

Fig. 7. Packet rate for loop 5 with influence of REIN.

presented three moments of significant and increasing loss between 25 and 35 seconds. These results strengthen the idea that the modem suffered a connection loss around that time instants. Such an effect is shown in Figure 8.

By analyzing the delay we can observe that loops 1 and 2 have achieved a more constant delay, however with a larger level when compared with the noiseless results. Loop 3 has presented a lower and more constant delay when compared with the noiseless tests. For loop 4 a similar delay level has been obtained, but more constant when compared with the noiseless case. Finally, loop 5 has shown a lower delay during the first seconds, tending, after that, to follow the level of the respective noiseless version.

After analyzing the results, it has been observed that packet rate (and consequently bit rate) and lost packets are the most affected variables by the impulse noise influence on ADSL2+ transmission. On the other hand, it is noted that the delay exhibits a strange behavior (decreasing values) for upstream in loops with bridge-taps. Additionally, by observing the packet rate and lost packet results, both for upstream and downstream, we can see that downstream is more sensitive than upstream to noise influence.

2) QoE Results: The idea of these tests is to perform a subjective evaluation of REIN impact on video transmission, by analyzing videoconference calls, transfer of on-line video streams, and network game (of the type client-server). The aim is to label the video services 


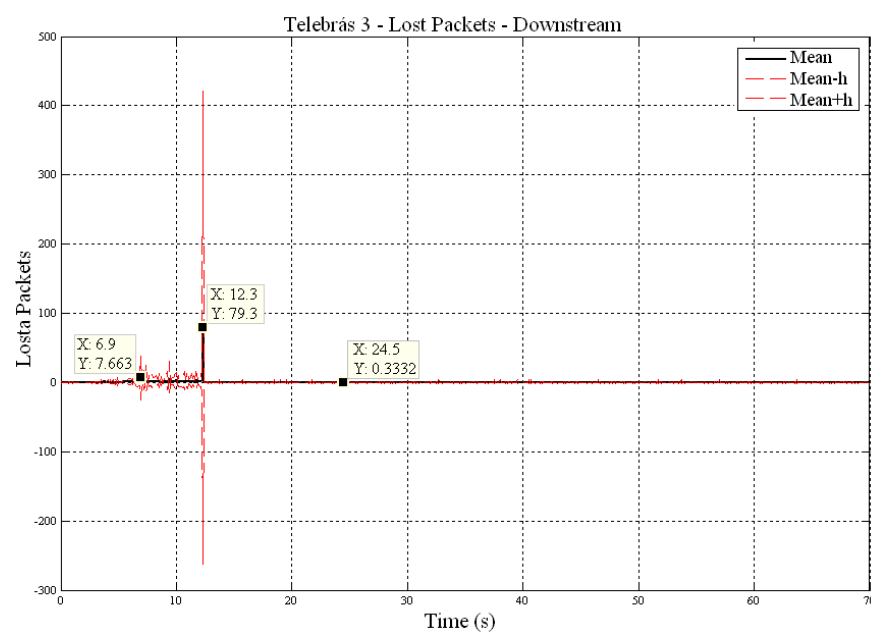

Fig. 8. Lost packets for loop 3 with influence of REIN.

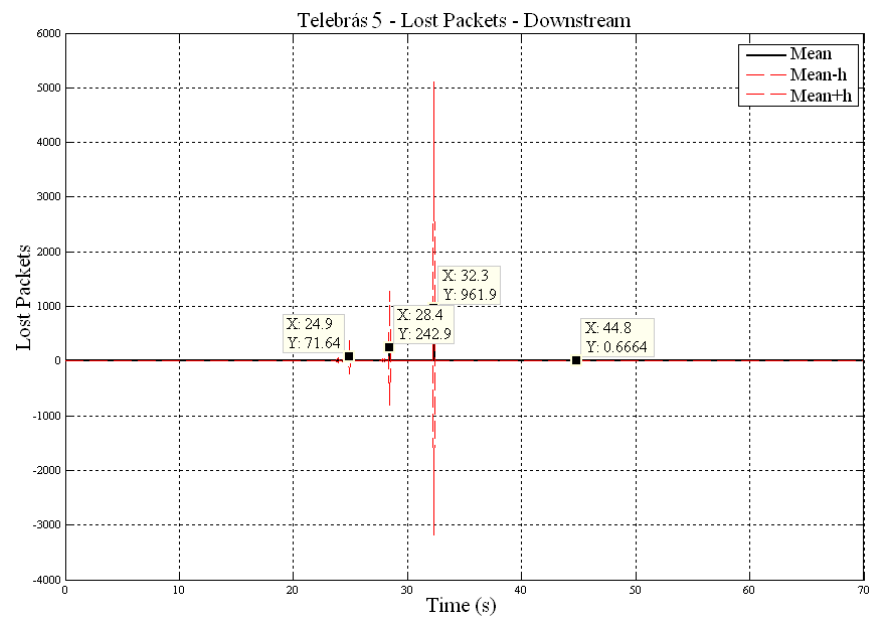

Fig. 9. Lost packets for loop 5 with influence of REIN.

according to Table III, proposed for MOS rating. Nevertheless, the results presented in this paper were achieved in an indirect way, by using QoS figures. Basically, we have performed a QoS analysis and then evaluate the QoS parameters correlation with service quality for the final user. The latter had been obtained by a simplified subjective analysis where just one or two subjects gave opinions. Another important thing to know is that the results of QoE consider only loop 1 of Telebrás standard.

Table III

MOS CLASSIFICATION FOR VIDEO USER EXPERIENCE [23]

\begin{tabular}{c|c}
\hline \hline Numerical Value & User Experience \\
\hline 5 & Not Perceptible \\
\hline 4 & Perceptible but not Annoying \\
\hline 3 & Perceptible \& Slightly Annoying \\
\hline 2 & Perceptible \& Very Annoying \\
\hline 1 & Perceptible \& Extremely Annoying \\
\hline \hline
\end{tabular}

As said previously, the QoE tests consider two profiles of REIN:

- Duration of $1 \mathrm{~ms},-85 \mathrm{dBm} / \mathrm{Hz}$ PSD and 1 occurrence per second;

- Duration of $100 \mu \mathrm{s},-95 \mathrm{dBm} / \mathrm{Hz}$ PSD and 100 occurrences per second.

Concerning the first profile we can not observe significant changes in the services of videoconference (using Skype) and video online on demand (accessing CNN site), classifying these services as level 5 according to Table III. However, for tests with access to sites that use buffer to load video (You Tube) we observed that sometimes the video is not loaded completely, so the impact of noise in this case is evident and slightly annoying, classifying the service as level 3 according to Table III.

Repeating the same analysis to the second noise profile, we can observe in all situations an extremely perceptible and annoying impact. In such situations, we have noticed connection losses of the modem which tries readily to connect again. Nevertheless, when a modem conection loss happens, video visualization is completely disabled. Additionally, in the tests with videos on demand we have noticed that audio service dropps first than video service. Thus, this service has been classified as level 1 (MOS scale).

Regarding to the tests with network game, no impact caused by the first REIN profile has been perceived. The ping has remained at acceptable levels and no alteration in the game has been noticed, then resulting in a level 5 classification. In turn, when the second REIN profile is used, an extremely perceptive impact on the game is observed due to recurrent modem connection losses. In such cases, as expected, the ping values vary severely which results in a level 1 classification, meaning impossibility to play.

\section{CONCLUSION}

This paper has presented an experimental analysis of the IN impact on DSL transmission. The results have shown that $\mathrm{C} 1$ and $\mathrm{C} 2$ impulses with amplitudes up to $100 \mathrm{mV}$ are not appropriate for DSL performance tests. Layer 3 IP Metrics, such as packet rate and lost packet count, are also not suitable for detailed analysis of IN impact.

Concerning to the tests with REIN, considering QoS analysis, we have perceived a significant influence of that kind of noise mainly in the packet rate, lost packet and bit rate. Experimental data suggest that the system is more sensitive to lost packets, which can cause severe system degeneration, as connection loss. At QoE level, we have observed that loop 1 is more robust to noise than the others for the first REIN profile, considering the tested applications, with exception of the buffered video where sometimes we did not get to watch all the video.

With these results we conclude that constant variations in the QoS variables do not seem to be associated with important degradations on the user experience, probabily because the modem acomplishes to adapt itself. On the other hand, the second REIN profile caused a severe impact on perceived service quality, resulted by recurrent modem connection losses. Thus, the system seems to be more affected by periodicity of this interference and not by its power or duration. We can also observe that the QoS variable that is more related to the user experience in video applications is the lost packets.

As research next steps, we intend to: investigate a possible perceptual REIN threshold, extend these (and others) QoE tests for the rest of loops cited in this paper, perform tests with burts of impulses, and concuct actual subjective assessment of application perceived quality in order to obtain a QoE test bed for future evaluation of representativeness of QoS figures.

Further studies are in progress to analyze the impact of other kinds of IN on DSL transmission. Measurements of IN impact for multimedia applications, such as VoIP and IPTV are also been performed.

\section{ACKNOWLEDGMENT}

Authors would like to thank the Research and Development Centre, Ericsson Telecomunicações S.A., Brazil, Federal University of Pará, 
Department of Electrical and Computer Engineering, Belém, Pará, Brazil. And Ericsson AB, Access Signal Processing Laboratory, Älvsjö, Sweden. Some of the authors want to acknowledge the financial support received from the European Commission IST 6th Framework and from the Swedish Agency for Innovation Systems, VINNOVA, through the IST - MUSE and the Eureka - Celtic BANITS projects respectively, which partially enabled this work.

\section{REFERENCES}

[1] T. Starr, J. M. Cioffi, and P. J. Silverman, Understanding Digital Subscriber Line Technology, Upper Saddler River, NJ: Prentice Hall, 1999.

[2] W. Wallace, L. Humphrey, R. Kirkby, and C. Pitt, Enhanced DSL Algorithms - Deliverable number DB2.2, MUSE (Multi-Service Access Everywhere) Project, December 2005.

[3] R. Stolle, Electromagnetic Coupling of Twisted Pair Cables, IEEE Journal on Selected Areas in Communications, vol. 20, pp. 883-892, June 2002.

[4] P. Ödling, P. O. Börjesson, T. Magesacher, and T. Nordström, An Approach to Analog Mitigation of RFI, IEEE Journal on Selected Areas in Communications, vol. 20, pp. 974-986, June 2002.

[5] R. Locatelli, S. Brini, L. Fanucci, and C. Del-Toso, An Optimized Digital RFI Cancellation Scheme for DMT-based VDSL Systems, The 8th International Conference on Communication Systems, vol. 1, pp. 229-233, November 2002.

[6] F. Sjöberg, R. Nilsson, P. O. Börjesson, P. Ödling, B. Wiese, and J. A. C. Bingham, Digital RFI Suppression in DMT-Based VDSL Systems, IEEE Transactions on Circuits and Systems, vol. 51, pp. 2300-2312, November 2004.

[7] T. H. Yeap, D. K. Fenton, and P. D. Lefebvre, Novel Common Mode Noise Cancellation Techniques for xDSL Applications, IEEE Instrumentation and Measurement Technology Conference, vol. 1, pp. 1125-1128, May 2002.

[8] N. Nedev, S. McLaughlin, D. Laurenson, and R. Daley, ATM Cell Error Performance of $x D S L$ under Impulse Noise, IEEE International Conference on Communications, pp. 1254-1258, June 2001.

[9] N. Nedev, S. McLaughlin, D. Laurenson, and R. Daley, Data Errors in ADSL and SHDSL Systems due to Impulse Noise, IEEE International Conference on Acoustics, Speech, and Signal Processing, pp. 4048-4051, May 2002.

[10] N. Nedev, S. McLaughlin, and D. Laurenson, Estimating Errors in $x D S L$ due to Impulse Noise, IEEE International Zurich Seminar on Communications, pp. 148-151, February 2004.

[11] R. Boden, Simulating ADSL Transmission Performance under the Impact of Impulsive Noise, 12th GI/ITG Conference on Measuring, Modeling and Evaluation of Computer and Communication Systems / 3rd PolishGerman Teletraffic Symposium, September 2004.

[12] L. V. de Souza, D. L. Cardoso, M. S. Silva, M. C. Seruffo, D. Russillo, J. C. W. A. Costa, C. R. L. Francês, A. L. S. Castro, G. P. dos S. Cavalcante and J. R. I Riu, Impact of Non-Stationary Noise on xDSL Systems: an Experimental Analysis, Proceedings of SPIE - Fourth Symposium on Fluctuations and Noise, To be published, 2007.

[13] http://kb.lumison.net/?action=view_topic\&id=715, last access in April 21, 2007.

[14] ITU-T, Test Procedures for Digital Subscriber Line (DSL) Transceivers, ITU-T Recommendation G.996.1, February 2001.

[15] DSL Forum, ADSL Interoperability Test Plan, DSL Forum Technical Report TR-048, April 2002.

[16] ITU-T, Asymmetric Digital Subscriber Line (ADSL) transceivers - Extended bandwidth ADSL2 (ADSL2+), ITU-T Recommendation G.992.5, January 2005.

[17] J. Dias, I. Negrão, et al, "Improving the Performance Evaluation of ADSL systems by using a Modem Diagnosis Methodology", MOMAG 2006, Belo Horizonte-MG, September 2005.

[18] DSL Consortium - Network Access Verification Interoperability Test Suite (NAV), Version 1.3.1.

[19] DSL Forum, "ADSL Interoperability Test Plan", Technical Report TR067,2004

[20] DLS Test Works, “Operating Manual DLS 400E ADSL Wireline Simulator,'Rev. 7, 2000.

[21] Sistema de Documentação da Telebrás - Série Engenharia, Especificações Gerais de Modem Operando com Técnica de Transmissão Assimétrica (ADSL), nas Velocidades de 2048, 4096 e 6144 kbits/s - 2 Fios, April, 1997.
[22] Gibbons, R. D.: 1994, Statistical Methods for Groundwater Monitoring, John Wiley \& Sons, New York

[23] DSL Forum, Technical Report TR-126, Triple-Play Services: Quality of Experience (QoE) Requirements, December, 2006.

[24] ITU-T Study Group 12 - Performance and quality of service. Question 12 Study Period 2005-2008: http://www.itu.int/ITUT/studygroups/com12/index.asp., last access in April 25, 2007.

[25] ITU-T Study Group 12,Question 13/12 - Multimedia QoE/QoS performance requirements and assessment methods: http://www.itu.int/ITUT/studygroups/com12/sg12-q13.html., last access in April 25, 2007.

[26] IPTV Interoperability Forum (IIF), Alliance for Telecommunications Industry Solutions (ATIS) workgroup: http://www.atis.org/iif/index.asp., last access in April 25, 2007.

[27] http://www.skype.com. Last access in April 25, 2007.

[28] http://www.youtube.com. Last access in April 25, 2007.

[29] http://www.cnn.com/video. Last access in April 25, 2007. 